\title{
Design and Research for the Water Low-pressure Large-flow Pilot-operated Solenoid Valve
}

\author{
Liu Lei ${ }^{1}$ - Zhang Desheng2,3 - Zhao Jiyun ${ }^{1, *}$ \\ ${ }^{1}$ China University of Mining and Technology, School of Mechanical and Electrical Engineering, China \\ 2 Coal Mining Technology Department, Tiandi Science and Technology, China \\ ${ }^{3}$ China University of Mining and Technology Beijing, School of Mechanical Electronic \& Information Engineering, China
}

\begin{abstract}
The basic requirements of the valve-control coupling for control valves are quick response, high flow capacity, and anti-blocking ability. In this article, a pure water hydraulic test-bed is built, and the pressure distribution characteristics between the throttle nozzle and the pilot valve, as well as the flow characteristics in the throttle orifice are researched. Following that, the water medium low pressure large-flow pilot operated solenoid valve is designed. The influences of throttle nozzles' diameter and other parameters on the dynamic and static characteristics of the valve are analysed via AMESim simulation software. The optimized combination of parameters of the solenoid valve group is determined. The experiment results show that the normal working pressure drop of the designed solenoid valve group is approximately $0.07 \mathrm{MPa}$, the opening time is 0.3 to $0.4 \mathrm{~s}$, the closing time is approximately $1 \mathrm{~s}$; it possesses better low pressure characteristics and rapid response characteristic, which can satisfy the requirements of valve-control coupling.
\end{abstract}

Keywords: water medium, low pressure, large-flow, pilot operated solenoid valve, throttle orifice, main valve structure

\section{INTRODUCTION}

In hydraulic systems, a pure water hydraulic system is a new development direction in fluid transmission and control field [1] and [2]. Compared with conventional mineral hydraulic oil, water as a medium has certain unique advantages, such being clean/non-polluting, easily available and resistant to explosion [3]; it has been increasingly used widely in food, fire, high pressure cleaning, reactor, mining and other industries [4] and [5]. Recent research on water electromagnetic valves has mostly focussed on high-pressure valves [6], rather than on low-pressure large-flow valves. Meanwhile, most of the research is on the flow field characteristics of existing valves, but little has been done on the structural design of valves.

Low-pressure large-flow valves with fast response characteristics are highly valued in industrial applications, such as high-power valve-control coupling, in which low-pressure large-flow solenoid valves are a core component. It helps to achieve gentle starts of valve-control coupling by controlling the liquid-filling processes. The working liquid can be replaced in a timely manner according to the liquid temperature and pressure in the chamber to control the speed and limit the working temperature. Valvecontrol coupling has been widely used in heavy scraper conveyors of coal mines, belt conveyers, pump, draught fans and other heavy equipment; it plays an important role in improving working conditions and saving energy [7] and [8]. The lowpressure large-flow valve group is one of the key factors of high-power valve-control coupling.
The control valve for valve-control coupling can be classified as a solenoid valve. Low-pressure largeflow solenoid valves with piston liftd and diaphragms are both using pilot valves structure. Some research about solenoid valve for valve-control coupling provides a good basis for this study [9] to [11]. Other related research about valve design [12], simulation [13] and improvement [14] is also encouraging. However, the application requirement of the solenoid control valve group is stricter in some difficult operating environments.

This article describes low-pressure large-flow pure pilot-operated water solenoid valves (the flow is larger than $240 \mathrm{~L} / \mathrm{min}$ ) according to the working requirements of the valve-control coupling. The effect of key parameters on valve group characteristics is analysed using AMESim in order to seek reasonable parameters. The pure water hydraulic test platform is set up to carry out experimental verification.

\section{WORKING PRINCIPLE OF THE SOLENOID VALVE GROUP}

\subsection{Working Principle of Differential Pressure Type Pilot Operated Solenoid Valve}

The differential pressure type pilot-operated solenoid valve is constituted with a main valve and a solenoid pilot valve, as seen in Fig. 1.

In the pilot hydraulic half-bridge, $R_{1}$ and $R_{2}$ represent the throttle orifice fluid resistance and the pilot valve fluid resistance, respectively. Both are connected in series. The supply fluid pressure is $p_{1}$, 
and upper chamber pressure of the main spool is $p_{2}$. The relationship between them is:

$$
p_{2}=\frac{R_{2}}{R_{1}+R_{2}} p_{1}
$$

The role area of the control chamber (upper chamber) is $A_{2}$. The role area of the high-pressure chamber (lower chamber) is $A_{1}$. Here $A_{1}<A_{2}$. The spring stiffness in the upper chamber is $k$.

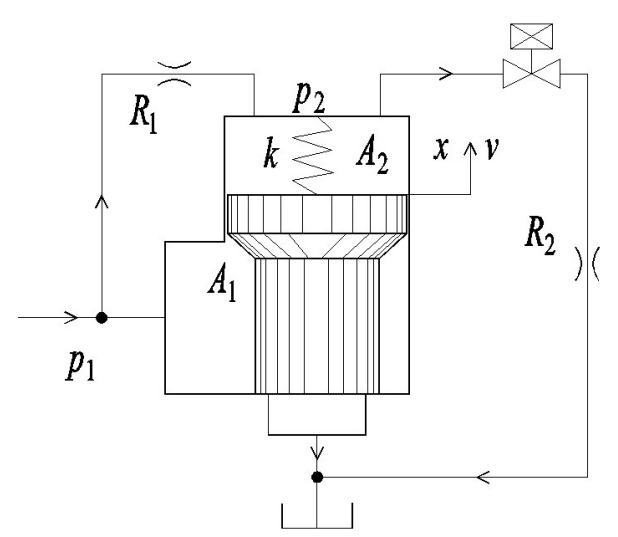

Fig. 1. Working principle of pilot operated solenoid valve

When the pilot valve is closed, the working medium flows into the upper chamber through the orifice, and it cannot continue because of resistance. The fluid resistance $R_{2}$ is infinite at this time. From Eq. (1) it can be known that $p_{1}$ is equal to $p_{2}$. The greater the work pressure, the tighter seal.

When the pilot valve is opened, the pressure drops are formed at the orifice and the pilot valve. So $R_{2}$ is small, and by the Eq. (1) it can be known that $p_{1}$ is greater than $p_{2}$. When $p_{1}$ can overcome, the summation of $p_{2}$, spring force and friction brought by spool movement, the main spool will open.

\subsection{Spool Motion Equation}

The Spool motion equation is:

$$
p_{1} A_{1}-p_{2} A_{2}=m \ddot{x}-D_{1} \dot{x}+k\left(x_{0}+x\right)+F_{f}+F_{s} .
$$

Here $m$ is the spool's mass, $x$ is spool displacement, and $x_{0}$ is spring precompression. $D_{1}$ is damped coefficient. $F_{f}$ is the friction force. $F_{s}$ is flow force.

The static equilibrium condition before main valve opening is:

$$
p_{2} A_{2}+k x_{0}+F_{f}=p_{1} A_{1} .
$$

$$
\begin{aligned}
& \text { Define } \frac{A_{2}}{A_{1}}=k_{1}, \frac{R_{1}}{R_{2}}=k_{2} \text {, thus } \\
& A_{1} p_{1}\left(1-\frac{k_{1}}{1+k_{2}}\right)=k x_{0}+F_{f} .
\end{aligned}
$$

Ignore the spring force and the frictional force. Thus: $k x_{0}+F_{f}=0$.

And open the parameters condition:

$$
R_{1}>\left(k_{1}-1\right) R_{2} \text {. }
$$

Then it is expressed by pressure:

$$
\Delta p_{1}>\left(k_{1}-1\right) \Delta p_{2} \text {. }
$$

If the pilot valve flow capacity is strong, which means $R_{2}$ is 0 , the opening pressure parameter condition is:

$$
p_{1}>\frac{\left(k x_{0}+F_{f}\right)}{A_{1}} .
$$

As can be seen from Eq. (6), the spring mainly affects the opening pressure. In consideration of the reset, the smaller pre-tightening force is required because of the reducing opening pressure.

\subsection{Characteristics of Throttle Orifice}

The diameter $d$ and length $l$ are two basic parameters of the throttle nozzle. When the $l / d$ (length diameter ratio) is between 0.5 and 4 , it is called a 'short orifice'. When $l / d$ is greater than 4 , it is called a 'thin long orifice'. The short orifice flow calculation equation is similar to that of the thin-walled holes.

$$
q=C_{d} a_{0} \sqrt{\frac{2 \Delta p}{\rho}} .
$$

In the equation, $a_{0}$ is the cross-sectional area of the orifice. $C_{d}$ is flow coefficient, which is approximately 0.8 when the Reynolds number is larger. $\Delta p$ is the pressure difference at orifice.

Regarding laminar flow in the thin long orifice, the flow through circular tube calculation equation is:

$$
q=\frac{\pi d^{4}}{128 \mu l} \Delta p
$$

Therefore, the flow rate equation of the orifice Eqs. (1) and (2) can be summarized as:

$$
q=C a_{0} \Delta p^{m} .
$$


The coefficient $C$ is determined by the shape and dimensions of the orifice and the general nature of the liquid. The coefficient $m(0.5<m<1)$ is determined by the length diameter ratio of the orifice. The orifice is at the transitional state of laminar flow and viscous flow.

\subsection{Fluid Resistance Characteristic}

According to the working principle of the pilot solenoid valve, the pressure distribution test system is shown in Fig. 2. The pilot valve and throttle nozzle are connected in a series to simulate the relationship between the throttle nozzle and the pilot valve. The characteristics of 'pressure difference-flow' and the pressure distribution rule for the throttle nozzle and pilot valve are investigated using this test system. The solenoid pilot valve is turned on while electrified. Fig. 3 . shows the throttle nozzle structure.

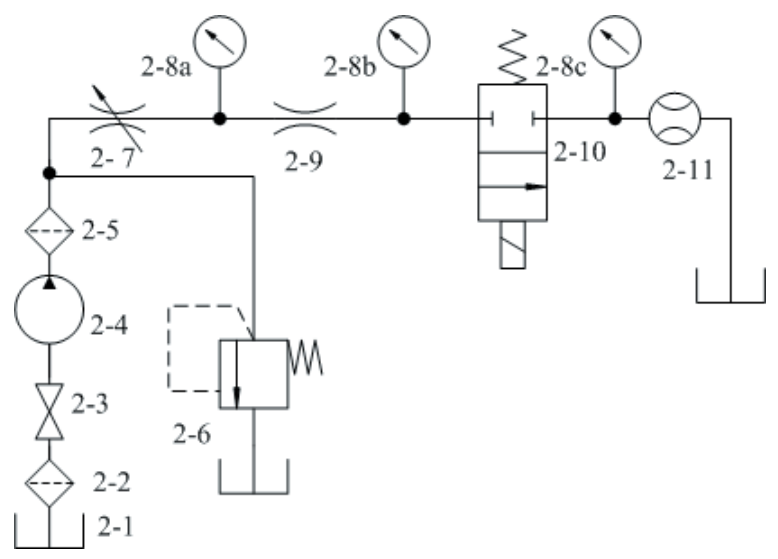

Fig. 2. Water hydraulic system for pressure dividing test

Adopt 2, 1.8, 1.5 and $1.2 \mathrm{~mm}$ four different throttle nozzles matching $3 \mathrm{~mm}$ pilot valve. Select 1.2 $\mathrm{mm}$ diameter throttle nozzle matching $1.5 \mathrm{~mm}$ pilot valve. Then compare the matching effect.

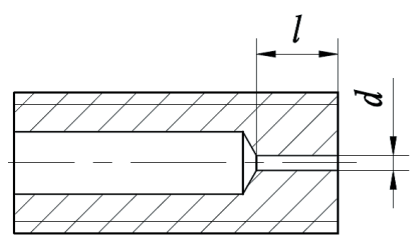

Fig. 3. Throttle nozzle structure

\subsection{Flow Characteristics of Throttle Nozzle}

The diameters of throttle nozzles are $1.2 \mathrm{~mm}$, and the lengths are 3.5, 5, 6 and $7 \mathrm{~mm}$ respectively. Fig.
4 is pressure-flow curves of different nozzle lengths, which shows that with increasing length of throttle nozzle, the flow capacity of the orifice is weakened. However, with further increases, the rate of flow decreases become slower. This means that sensitivity of the flow capacity is reduced according to the length.

When the flow coefficient $C_{d}$ is 0.7 , the theoretical value of throttle nozzle is calculated by using Eq. (7) as plotted in Fig. 4. It shows that the theoretical value is significantly larger. Although the effect of length on the flow characteristics is not considered in Eq. (7), it can also be seen that the overall trend of each experimental curve substantially presents the exponent distribution law, which means that the flow of the water medium in the orifice is a turbulent-state flow.

As the viscosity of water is small, the resistance loss along the way of the orifice is also low. The flow through the throttle nozzle is hardly affected by the viscosity in the test range, which means it is insensitive to change for water temperature. The temperature of water in the valve-control coupling changes tremendously in start and overloading conditions. Therefore, the feature is particularly suitable for valve-control coupling.

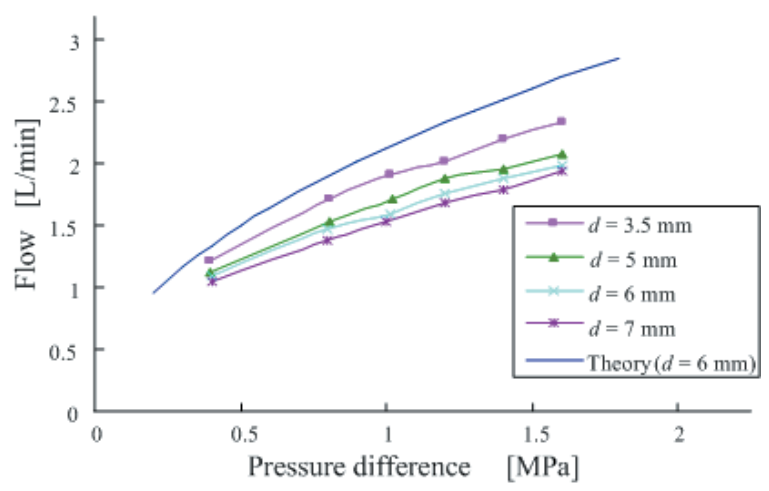

Fig. 4. Pressure-flow curves of different nozzle lengths

When diameters of the throttle nozzle are 1.2, 1.5, 1.8 and $2 \mathrm{~mm}$, the length diameter ratio is 3.5 , and the corresponding lengths are 4.2, 5.2, 6 and $7 \mathrm{~mm}$, respectively. Characteristics of flow in each throttling nozzle are shown in Fig. 5. It can be seen that in case of the same length diameter ratio, the larger the diameter, the stronger flow capacity. In accordance with the principles of the least squares method, fitting every pressure-flow curve according to the exponent function, here the exponent is approximately 0.5, which is closer to Eq. (9) and meets the flow characteristics of a short orifice. 


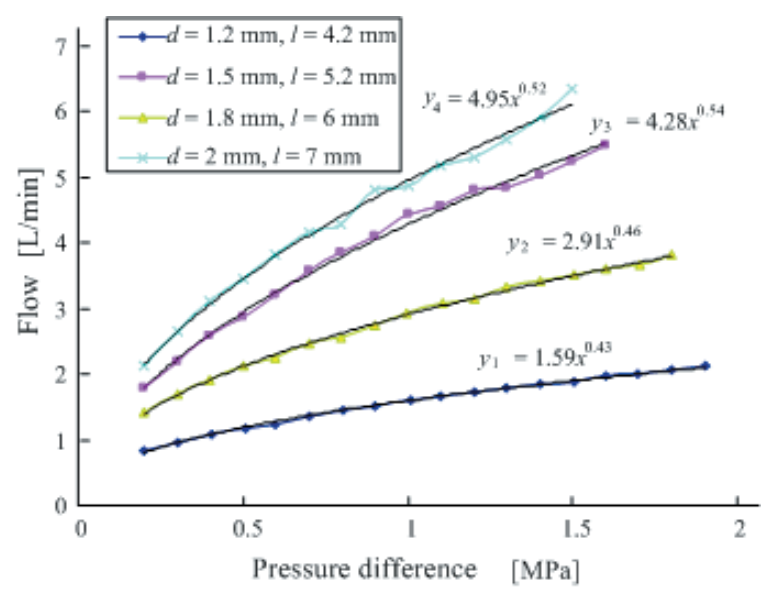

Fig. 5. Pressure-flow curves of different nozzle diameters

\subsection{Differential Pressure Distribution Rule}

Adopt four different throttle nozzles (2, 1.8, 1.5 and $1.2 \mathrm{~mm}$ ) with matching $3 \mathrm{~mm}$ pilot valves; the lengths of throttle nozzles are all $4 \mathrm{~mm}$. Fig. 6 shows pressure difference-flow curve.

Adopting a $1.2 \mathrm{~mm}$ orifice, when the system pressure is $1.9 \mathrm{MPa}$, the flow is $2.15 \mathrm{~L} / \mathrm{min}$. The pressure drop at the orifice accounts for the majority of the total pressure. As a result of the small flow, the pressure drop at the pilot valve is very small. When the pressure is $2 \mathrm{MPa}$ at orifice diameters of $1.5 \mathrm{~mm}$, the flow is $3.8 \mathrm{~L} / \mathrm{min}$. For a $1.8 \mathrm{~mm}$ orifice, when the pressure is $2 \mathrm{MPa}$, the flow is $5.5 \mathrm{~L} / \mathrm{min}$. When the pressure is $2 \mathrm{MPa}$ at orifice diameters of $2 \mathrm{~mm}$, the flow is $6 \mathrm{~L} / \mathrm{min}$. Therefore, when increasing the orifice diameter, the pressure drop of the pilot valve at the same flow rate is also increasing. Thus, the corresponding solenoid valve upper chamber pressure is increased. If the diameter of the orifice is further increased, the open condition of the Eq. (5) will not be satisfied.

In comparing Fig. 7 with Fig. 6, the pressure drop brought by a $1.5 \mathrm{~mm}$ diameter pilot valve nearly accounts for total pressure drop of $1 / 3$ for $1.2 \mathrm{~mm}$ throttle nozzle. However, the pressure drop proportion in total pressure brought by $3 \mathrm{~mm}$ diameter pilot valve is almost negligible. In considering the working pressure, the bigger diameter pilot valve should be selected.

\section{DESIGN OF THE MAIN VALVE}

Fig. 8 shows a hydraulic system of valve-control hydrodynamic coupling. It comprises a control system with an electro-hydraulic valve group as the main part
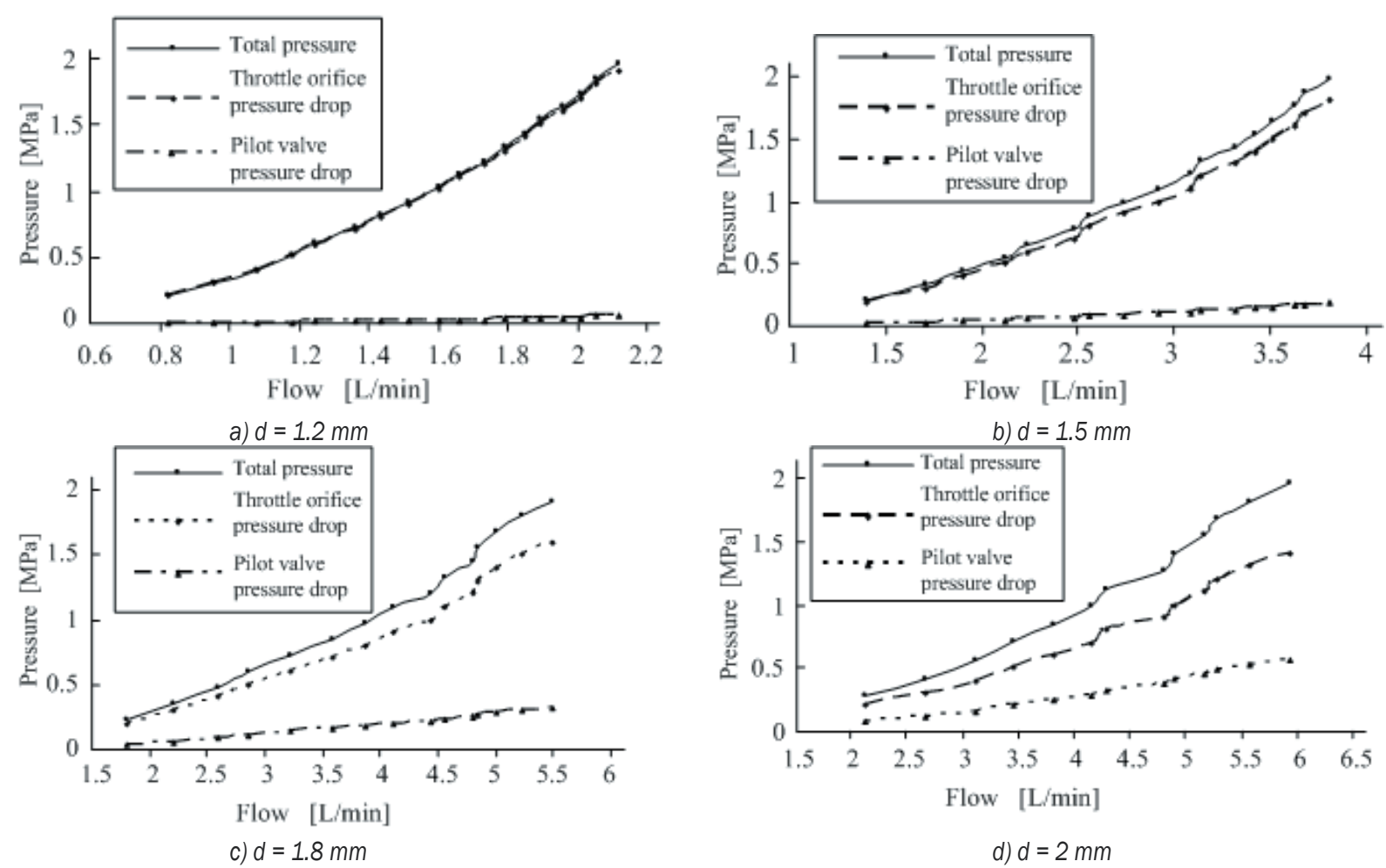

d) $d=2 \mathrm{~mm}$

Fig. 6. Pressure distribution between $3 \mathrm{~mm}$ pilot valve and different throttle nozzles 
and a hydrodynamic system taking coupling as the core part.

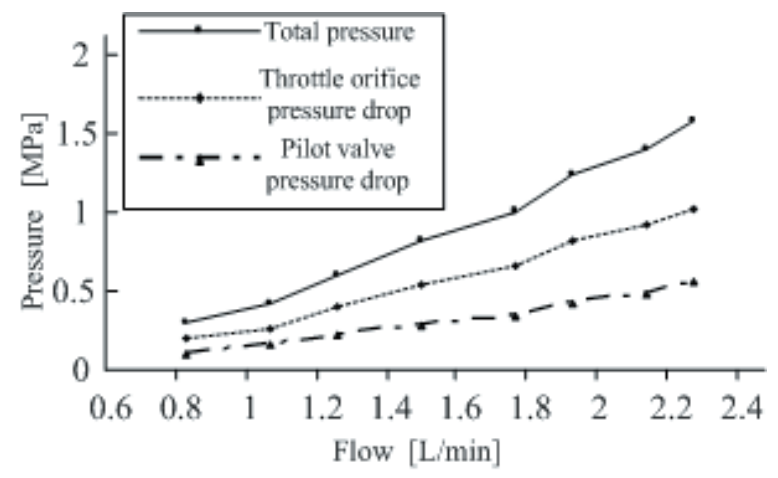

Fig. 7. Pressure distribution between $1.5 \mathrm{~mm}$ pilot valve and throttle nozzle $(d=1.2 \mathrm{~mm})$

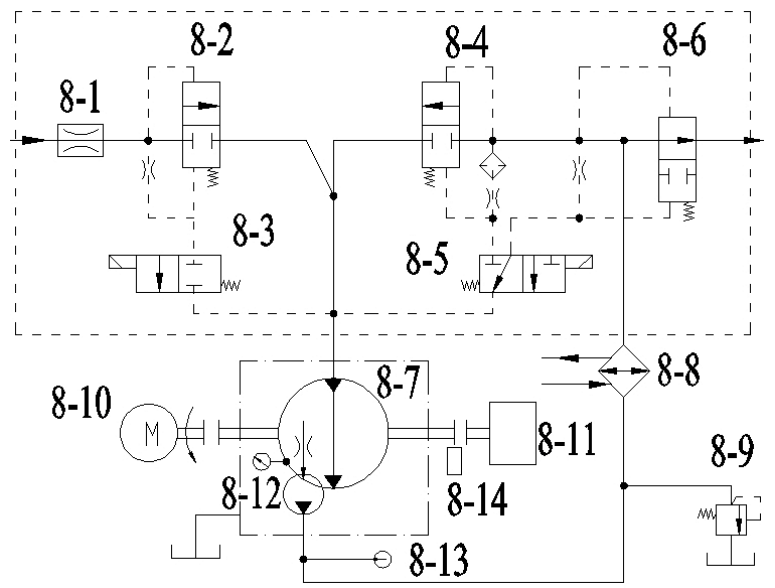

Fig. 8. Hydraulic system of valve-control hydrodynamic coupling; 8-1 flow controller, 8-2 filling valve, 8-3 solenoid pilot valve (2-position 2-way), 8-4 circulating valve, 8-5 solenoid pilot valve (2-position 3-way), 8-6 discharging valve, 8-7 coupling, 8-8 cooler, 8-9 relief valve, 8-10 motor, 8-11 load, 8-12 pressure transducer, 8-13 temperature transducer, 8-14 velocity transducer

The control valve group works according the pressure-difference pilot principle. It consists of the filling valve (8-2), the liquid-discharged valve (8-6) and the circulating valve (8-4). The pilot valve (8-3) controls the filling valve (8-2). The solenoid valve (83 ) is used as a pilot valve, and the filling valve (8-2) is used as the main valve. There is a damping orifice on the main spool. When the solenoid valve (8-3) is opened, there will be a pressure difference between the upper and lower cavities, the main valve will open under the action of pressure difference, and then the coupling will be filled with liquid. The two-position three-way solenoid pilot valve (8-5) can control both the on-off state of the circulating valve (8-4) and the on-off state of the discharging valve (8-6). The circulating valve and the liquid-discharged valve have the same principle as the liquid-filled valve (82). The movement of the main spool is also caused by the pressure difference between the upper and lower cavities. The circulating valve is mainly to control the on-off state of coupling circuits, and the liquiddischarged valve is used to discharge the liquid inside coupling. Only one of the two valves could open under the action of the pilot valve (8-5).

The motor rotating speed is $1490 \mathrm{r} / \mathrm{min}$. The essence of the valve-controlled coupling catheter is a rotary jet pump [15]. Therefore, the theoretical maximal value that the coupling catheter can provide is approximately 0.6 to $0.88 \mathrm{MPa}$ [16].

For a pure plane structure (Fig. 9a), during the process of fast reversing of the spool, a sudden block will cause sharply pressure rising inside the tube and lead to strong shock and noise. In order to relieve shock and noise, a cone is set at outlet surface of the plane valve. The fixed damping orifice is put on the main spool. The parameters of the tail cone structure are shown in Table 1.

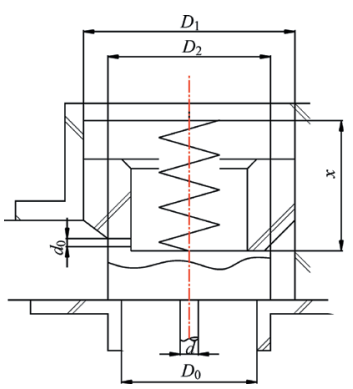

a) Pure plane structure

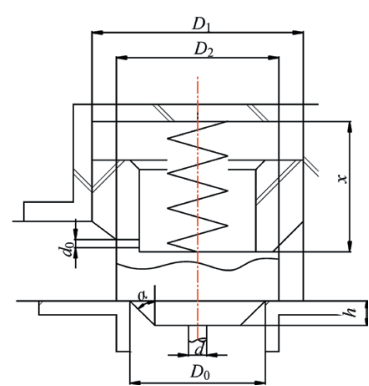

b) Tail cone structure
Fig. 9. Structure of the main spool

Table 1. Lists of parameters

\begin{tabular}{lccccccc}
\hline Parameters & $D_{0}$ & $D_{1}$ & $D_{2}$ & $D$ & $H$ & $X$ & $\alpha\left[^{\circ}\right]$ \\
\hline Value $[\mathrm{mm}]$ & 44 & 63 & 54 & 12 & 9 & 34 & $45^{\circ}$ \\
\hline
\end{tabular}

\section{SIMULATION OF THE CHARACTERISTICS OF SOLENOID VALVE BASED ON AMESIM}

The liquid-filled valve is studied as a sample in order to investigate the influences of the throttle nozzle, spring and other parameters on the dynamic characteristics, static characteristics and opening pressure. Following that, the combination of optimized parameters of the solenoid valve group can be determined, and whether spool structure could satisfy the function requirements of valve-control coupling can also be checked. 


\subsection{Building a Simulation Model}

The simulation model of the liquid-filled valve is established in AMESim, as shown in Fig. 10. It is composed of a pilot-operated solenoid valve and an external fluid supply system. The fluid supply system is provided liquid by a quantitative pump, and the fluid supply pressure is regulated by a relief valve. The stationary liquid resistance represents the characteristics of a damping orifice. The combination of the plane valve and poppet valve represents the main spool with tail cone structure.

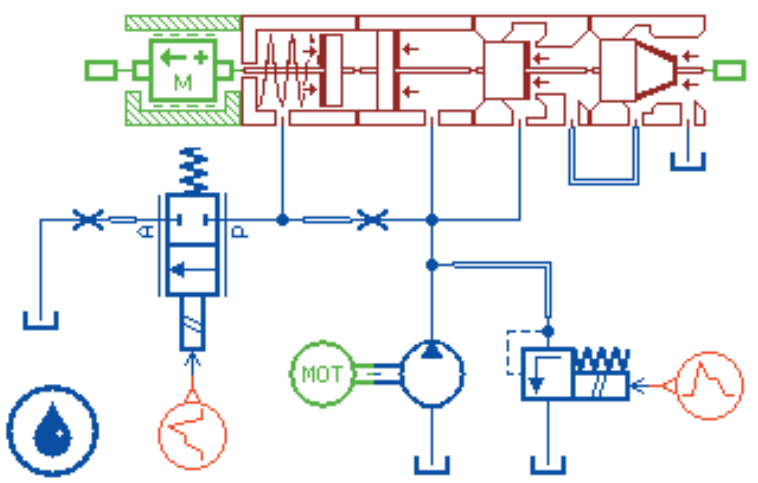

Fig. 10. Simulation model

\subsection{Simulation Results and Analysis}

\subsubsection{Opening Pressure}

The signal source is set to ensure that the opening pressure of relief valve increases linearly from 0 to 1.6 $\mathrm{MPa}$. In addition, the valve remains open while the pump flow rate is set to $240 \mathrm{~L} / \mathrm{min}$. The stationary liquid resistance is given by the pressure differenceflow data of a $3 \mathrm{~mm}$ pilot valve. The main spool spring stiffness is $10 \mathrm{~N} / \mathrm{mm}$. The pressure difference-flow data (obtained by the test) of 1.2, 1.5, 1.8 and $2 \mathrm{~mm}$ throttle nozzles are assigned to the liquid resistance.

It can be seen from Fig. 11 that before opening, the pressure at position A increased synchronously with the relief valve setting pressure. However, once opened, it declines sharply. The value of the inflection point is the minimum opening pressure. The opening pressure is about $0.16 \mathrm{MPa}$ when using a $1.2 \mathrm{~mm}$ throttle nozzle, $0.19 \mathrm{MPa}$ when using a $1.5 \mathrm{~mm}$ throttle nozzle and $0.225 \mathrm{MPa}$ when using a $1.8 \mathrm{~mm}$ throttle nozzle. The minimum opening pressure increases to $0.23 \mathrm{MPa}$ when using a $2 \mathrm{~mm}$ throttle nozzle. If the throttle nozzle is further enlarged, the opening pressure will rise further until it cannot be opened. In order to obtain a smaller opening pressure, considering the need of the anti-block ability, a 1.5 $\mathrm{mm}$ diameter throttle nozzle is selected.

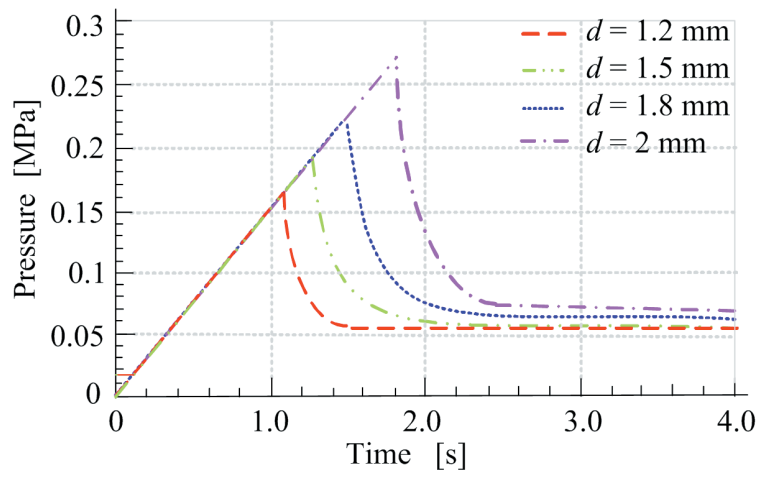

Fig. 11. Comparisons of opening pressure of different nozzle diameters

As a result of the main spool with a tail cone, it is necessary to observe the pressure at inlet B. Fig. 12 shows the pressure curves of position $\mathbf{A}$ and position B when using a $1.5 \mathrm{~mm}$ throttle nozzle. When the pressure is $0.13 \mathrm{MPa}$, the pressure at $\mathbf{B}$ begins to rise, and the pressure at $\mathbf{A}$ continues to increase with an increasing relief valve. When the pressure exceeds $0.13 \mathrm{MPa}$, the spool is slightly opened, and the relief valve is still working. However, the flow through the main spool is small, which is in the non-effective open state. The setting pressure of the relief valve continues to rise. When the opening pressure of the spool is 0.19 $\mathrm{MPa}$, the relief valve closes. Thus, all liquid comes through the main spool, the distance of the spool is further enlarged, the pressure drop appears at the valve orifice, which reduces until stability is attained. The pressure difference between position $\mathbf{A}$ and position $\mathbf{B}$ is the pressure drop produced by the plane valve. When spool is slightly opened, pressure drop is greater in the plane valve. When the relief valve is closed, the pressure drop at the plane circular throttle nozzle is less than $0.02 \mathrm{MPa}$.

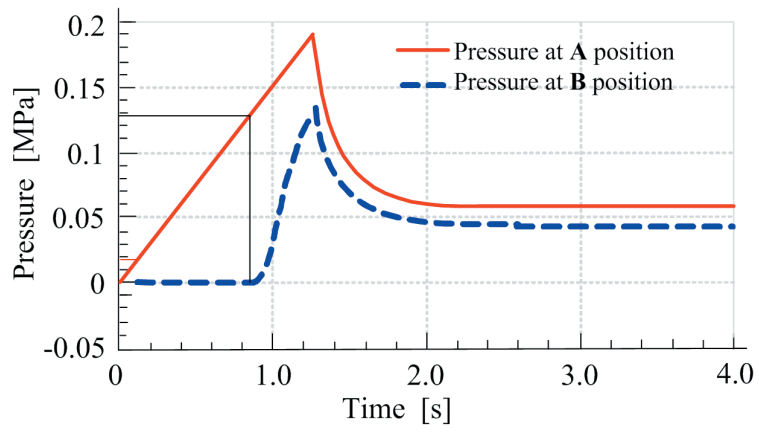

Fig.12. Comparison of opening pressures at two stages 


\subsubsection{Stable Pressure}

Pump flow is set to 240 and $400 \mathrm{~L} / \mathrm{min}$. The relief valve pressure is set to $1.6 \mathrm{MPa}$. The spring stiffness is set to $10 \mathrm{~N} / \mathrm{mm}$. Simulation time is $2 \mathrm{~s}$. Then, steady pressure at position $\mathbf{A}$ is observed.

Fig. 13 shows that the greater the flow and orifice, the greater the pressure drop at position $\mathrm{A}$. When the orifice is $1.2 \mathrm{~mm}$ and flow is $240 \mathrm{~L} / \mathrm{min}$, the pressure drop is minimum of $0.051 \mathrm{MPa}$. When the orifice is $2 \mathrm{~mm}$ and flow is $400 \mathrm{~L} / \mathrm{min}$, the pressure drop is maximum of $0.095 \mathrm{MPa}$. The pressure drop changes in a small range for each combination of parameters, which satisfies the requirements of low pressure and large flow.

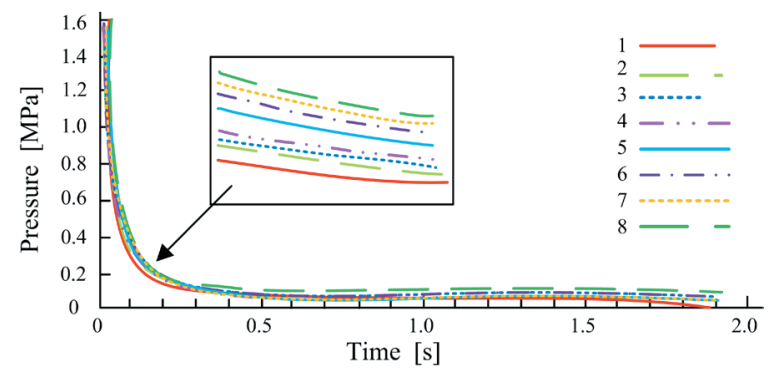

Fig. 13. Pressure drop (different flows and throttle nozzles); $1-Q=240 \mathrm{~L} / \mathrm{min}, d=1.2 \mathrm{~mm} ; 2-Q=240 \mathrm{~L} / \mathrm{min}, d=1.5 \mathrm{~mm}$; $3-Q=240 \mathrm{~L} / \mathrm{min}, d=1.8 \mathrm{~mm} ; 4-\mathrm{Q}=240 \mathrm{~L} / \mathrm{min}, d=2.0 \mathrm{~mm}$; $5-Q=400 \mathrm{~L} / \mathrm{min}, d=1.2 \mathrm{~mm} ; 6-\mathrm{Q}=400 \mathrm{~L} / \mathrm{min}, d=1.5 \mathrm{~mm}$; $7-Q=400 \mathrm{~L} / \mathrm{min}, d=1.8 \mathrm{~mm} ; 8-Q=400 \mathrm{~L} / \mathrm{min}, d=2.0 \mathrm{~mm}$;

\subsubsection{The Dynamic Response Characters}

The pressure of relief valve is set to $1.6 \mathrm{MPa}$; the flow is set to $240 \mathrm{~L} / \mathrm{min}$. The spring stiffness is set to $10 \mathrm{~N} / \mathrm{mm}$. The reversing valve of an on-off signal is given, and then the opening and closing time of the spool is studied. In order to measure and compare conveniently, the pressure at position $\mathbf{A}$ is taken as a reference (it would close down when it reaches to 1.6 $\mathrm{MPa})$. The comparison of response time of throttle nozzles in different diameters (1.2, 1.5, 1.8 and $2 \mathrm{~mm}$ ) are shown in Fig. 14; the blue line represents the input signal of the pilot valve, and high position represents 'on', zero position represents 'off'. Therefore, the smaller the throttle nozzle, the longer the closing time. The closing time is $2.6 \mathrm{~s}$ by using $1.2 \mathrm{~mm}$ throttle nozzle, and the closing time reduces to $0.75 \mathrm{~s}$ by using a $2 \mathrm{~mm}$ throttle nozzle. The open time is within $0.5 \mathrm{~s}$, which is hardly affected by the throttle nozzle.

The effect of different fluid supply pressure on the opening and closing characteristics are shown in Fig. 15. The throttle nozzle is $1.5 \mathrm{~mm}$ in diameter.
In the Fig. 15, it can be seen that the response curves of opening and closing process are overlapping. The closing time is about $1.2 \mathrm{~s}$ and the opening time is less than $0.5 \mathrm{~s}$. However, the opening time is close to closing time at different supply pressure. Furthermore, the fluctuation of fluid supply pressure has little effect on the overall response characteristics, i.e. this valve has good stability at low pressure.

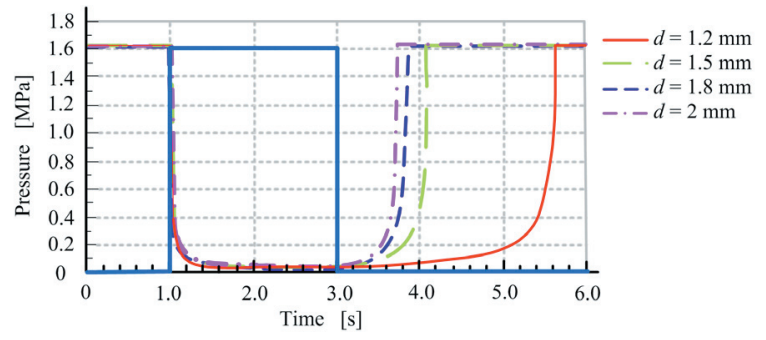

Fig. 14. Response characteristics (different throttle nozzles)

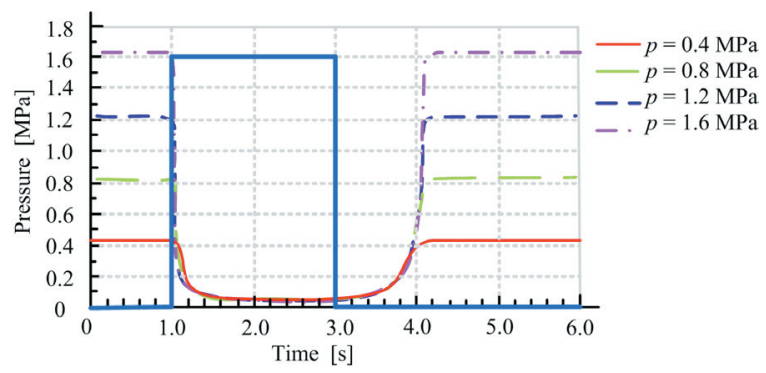

Fig. 15. Response characteristics (different supply pressure)

\section{EXPERIMENT AND DISCUSSIONS}

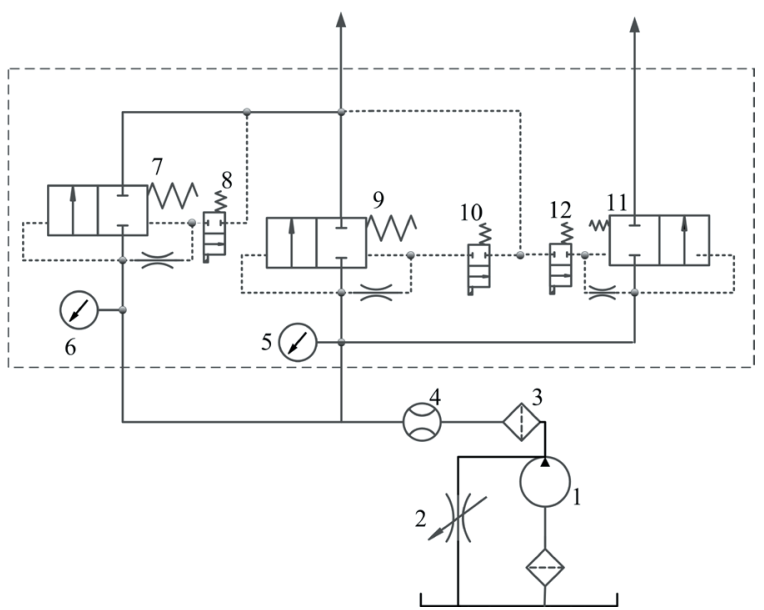

Fig. 16. Experimental system of valve group; 1 water pump; 2 throttle valve; 3 filter; 4 flowmeter; 5 pressure transducer; 6 pressure transducer; 7 filling valve; 8 solenoid pilot valve; 9 circulating valve; 10 solenoid pilot valve; 11 discharging valve; 12 solenoid pilot valve 
The principle of the valve group test system is shown in Fig. 16. The system pressure could be adjusted by manual throttle valve (2). The flow is $20 \mathrm{~m}^{3} / \mathrm{h}$. The head of delivery is $162 \mathrm{~m}$, the rotation rate is $2900 \mathrm{r}$ / min, and the power is $22 \mathrm{~kW}$.

The pressure, flow, and voltage signals are all collected with a data acquisition card. The collecting frequency is $1000 \mathrm{~Hz}$. In order to prevent the impurities blocking the main valve and pilot valve orifice, a filter (3) is set in the system

\subsection{Opening Pressure}

After adjusting the opening of the throttle valve (162) to maximum, the supply pressure reaches to the minimum; keep the pilot valve (16-8) in the electric state. The pilot valve is opened at this time. Slowly adjust the throttle valve so as to gradually increase the pressure. The change of pressure and flow can be observed. When the liquid flows out from the discharging valve, the opening pressure is minimum. When the valve opens, the pressure decreases. Therefore, it can be judged according to the record of the point of inflexion of pressure curve. The entrance pressure change of filling the valve is shown in Fig. 17. When the pressure is between $0.22 \mathrm{MPa}$ and 0.23 $\mathrm{MPa}$, a significant pressure drop appears, which means the valve is opening. Therefore, the opening pressure of filling the valve is approximately $0.22 \mathrm{MPa}$.

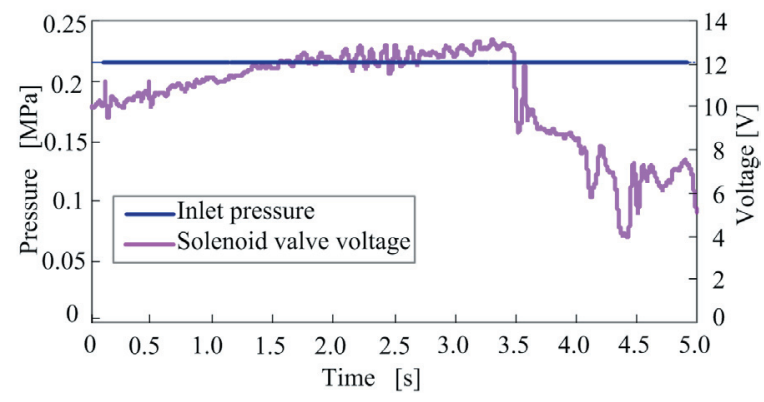

Fig. 17. Opening pressure

\subsection{Response Characteristics}

The inlet pressure is adjusted to $0.8,1.2$ and $1.5 \mathrm{MPa}$. The pressure change is studied on the process of the opening and closing of the spool under different pressures of the liquid supply, which are response characteristics. The opening and closing process are shown in two images. Fig. 18 shows that the opening (left) and closing (right) process under the different inlet pressures.
In the process of opening, the solenoid pilot spool opens immediately after the solenoid pilot valve is electrified. The inlet position of the main spool produces small pressure fluctuations along with sudden change of the solenoid valve, and the fluctuation is the stability process of the pilot spool. With the main spool opening, the pressure declines rapidly. When spool attains the maximum opening, an inflection point happens, after which the pressure gently declines. The process of the gentle decline is a new process of pressure balance that the pump reestablishes. Therefore, the opening process isfrom the electrified point to the pressure inflection point in Fig. $18 \mathrm{a}, \mathrm{b}$ and $\mathrm{c}$.

In the closing process, with the pilot valve closed, a pressure pulse appears first, and then the pressure rises after a straight section. A rapid decline and fluctuation appear after the high-point, and then the pressure gently rises. After the spool is completely shut down, it cannot be immediately restored to the pressure before opening. The process of the gentle rise after the pressure decline is a new process of pressure balance that the pump re-establishes. The fluctuation of the high-point is the impact and liquid returning as a result of the spool being completely closed. Thus, the closing process is from the electrified point to the highest pressure point in Fig. 18a, b and c.

The opening process is between 0.3 and $0.4 \mathrm{~s}$. The bigger the inlet pressure, the shorter the opening time; however, the changing amplitude is small, which is basically identical with Fig. 15. The time of closing process is around $1 \mathrm{~s}$, which contains two stages, straight and rise, and the trend and time are essentially identical with the AMESim simulation results in Fig. 15.

In Fig. 18, when the spool opens, it maintains in long period. Before closing, the pressure is under a stable condition, which is the low pressure flow characteristic. In different supply pressures of $0.8,1.2$ and $1.5 \mathrm{MPa}$, the stable flows are, respectively, 140 , 160 and $190 \mathrm{~L} / \mathrm{min}$. Before closing, the pressure is maintained approximately $0.1 \mathrm{MPa}$. When the flow is $190 \mathrm{~L} / \mathrm{min}$, the pressure loss is minimum, which is about $0.07 \mathrm{MPa}$. The value is close to that of pressure drop of $240 \mathrm{~L} / \mathrm{min}$ in the simulation process. When the flow is low, the fluid power is also small. In order to overcome the spring force, a larger pressure difference is needed. There will be a larger pressure drop, but the pressure is in the lower state.

The opening pressure is $0.22 \mathrm{MPa}$. When flow is $190 \mathrm{~L} / \mathrm{min}$, the stable pressure is $0.07 \mathrm{MPa}$. Meanwhile, the opening time is about 0.3 to $0.4 \mathrm{~s}$. 

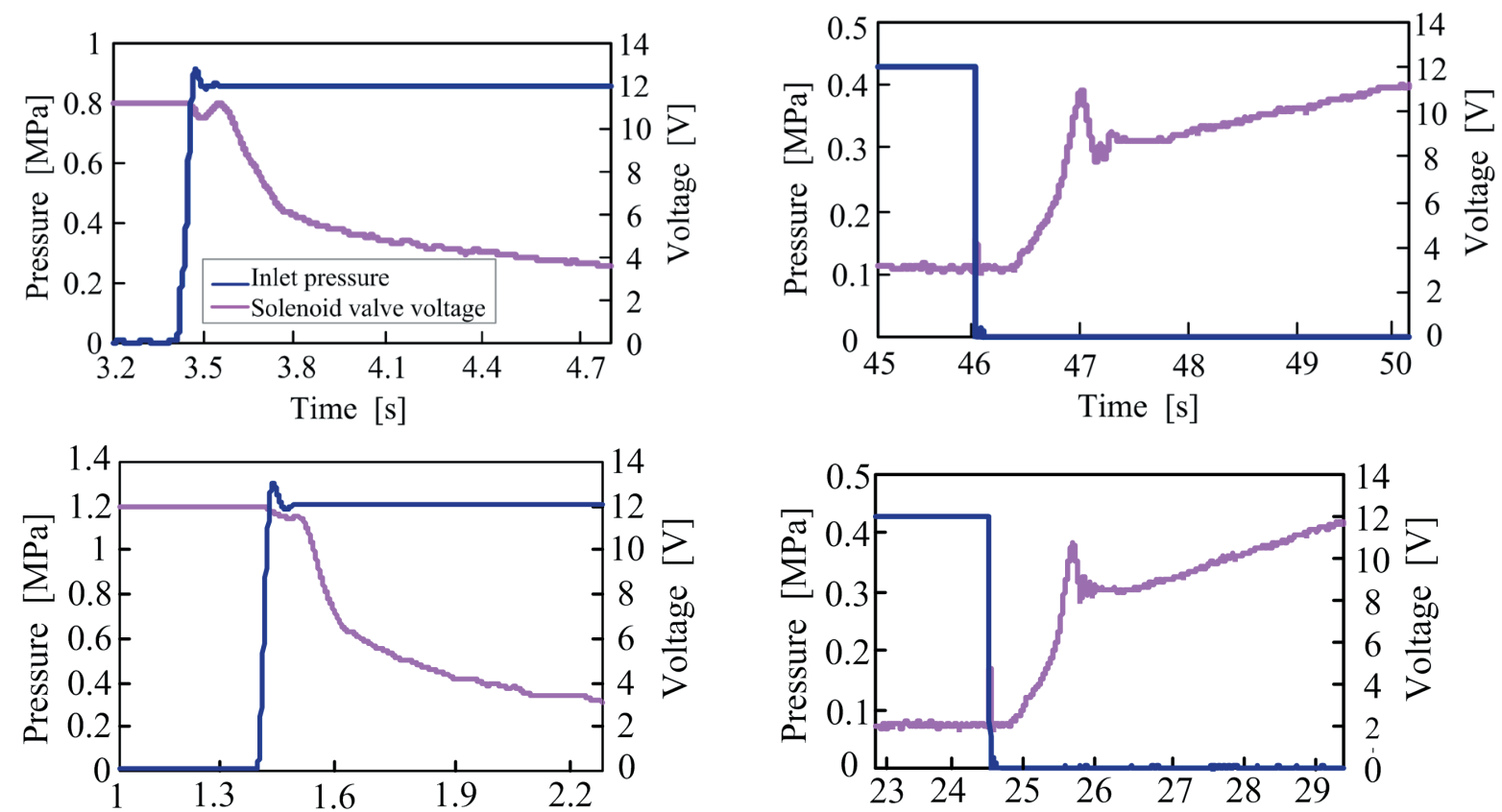

b)

Time [s]
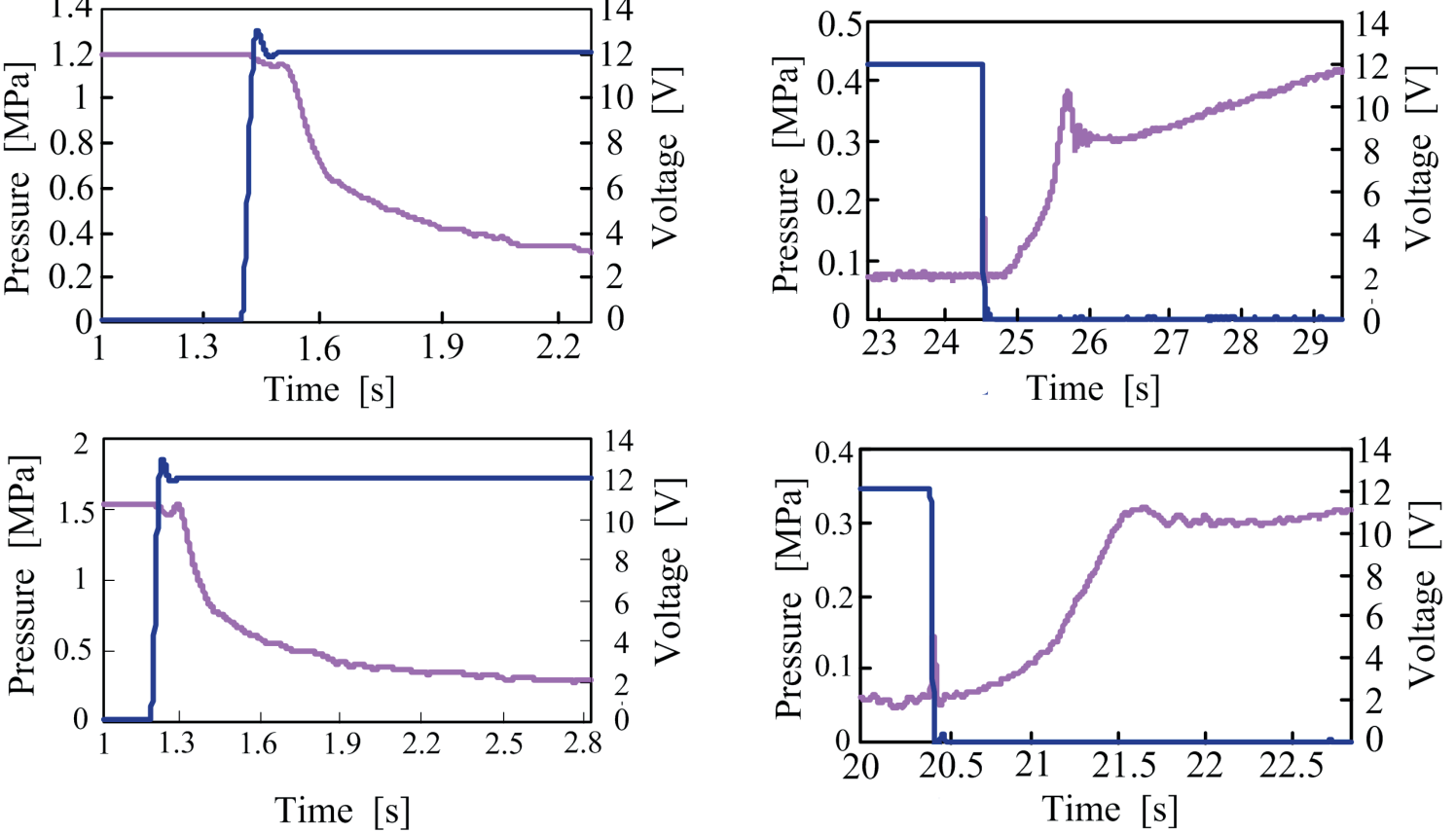

c)

Time [s]

Fig. 18. Opening (left) and closing (right) characteristics at different inlet pressures; a) $0.8 \mathrm{MPa}$; b) $1.5 \mathrm{MPa}$; and c) $1.2 \mathrm{MPa}$

The closing time is about $1 \mathrm{~s}$. The circulating liquid entrance response time is about $1.1 \mathrm{~s}$.

The test results show that the designed solenoid valve possesses better low-pressure characteristics and rapid response characteristics.

\section{CONCLUSIONS}

Based on the logic relations of the filling valve, circulating valve and discharging valve, we designed the pilot-operated solenoid valve group. The radial seal of main valve is adopted co-axial seal (Gelai ring), and the end face seal is adopted a plane soft seal, in order to adapt to the characteristics of the water medium. Two-stage throttling of plane and cone structure can reduce the impact during the process of opening and closing. The simulation model of filling the valve is established via AMESim. The influence of liquid damping on static and dynamic characteristics for the control valve is studied. The simulation results show that the response time is decided by the diameter of throttle nozzle and the spring stiffness (the bigger the diameter of the throttle nozzle and the spring rigidity, the faster the response), and with little influence of the supply pressure. The opening pressure and stable working pressure of the single valve are both small, which satisfies the demand of low pressure and high flow.

\section{ACKNOWLEDGMENTS}

This work is supported by Specialized Research Fund for the Doctoral Program of Higher Education (20130095110012). 


\section{REFERENCES}

[1] Scheffcls (1996). Developments in water hydraulics. Hydraulics \& Pneumatics, no. 12, p. 33-34.

[2] Koskinen, K.T., Vilenius, M.J. (1998). Water hydraulics-A versatile technology. Journal of the Japan Hydraulics and Pneumatics Society, vol. 29, no. 7, p. 597-603.

[3] Yang, H.Y., Gong, Y.J., Zhou, H. (2004). Development review of water hydraulic valve. China Mechanical Engineering, vol.15, no. 15, p. 1400-1404. (in Chinese)

[4] Urata, E. (1999). Technological aspects of the new water hydraulic. The $6^{\text {th }}$ Scandinavian International Conference on Fluid Power, Tampere, p. 21-34.

[5] Backe, W. (1999). Water-or-oil hydraulics in the future. Proceedings of $6^{\text {th }}$ Scandinavian International Conference on Fluid Power, Tampere, p. 51- 64.

[6] Tang, G.Q., Tao, J., Wang, J., Zhu, Y.Q. (2008). Development of a pure water pilot-operated on-off solenoid hydraulic valve. Chinese Hydraulics \& Pneumatics, no. 7, p. 68-70. (in Chinese)

[7] Song, W.G. (2007). Control-valve liquid type hydraulic coupling based on the different needs. Coal Engineering, no. 9, p. 107-110. (in Chinese)

[8] Lauhoff, H. (2005). Speed control on belt conveyor does it really save energy. Bulk Solids Handling, vol. 25, no. 6, p. 368-377.

[9] Majdič, F., Pezdirnik, J., Kalin M. (2011). Experimental validation of the lifetime performance of a proportional $4 / 3$ hydraulic valve operating in water.
Tribology International, vol. 44, no. 12, p. 2013-2021, DOI:10.1016/j.triboint.2011.08.020.

[10] Majdič, F., Velkavrh, I., Kalin, M. (2013). Improving the performance of a proportional $4 / 3$ water hydraulic valve by using a diamond-like-carbon coating. Wear, vol. 297, no. 1-2, p. 1016-1024, DOI:10.1016/j. wear.2012.11.060.

[11] Majdič, F., Kalin, M. (2014). Test rig and comparison of pressure changes at transient phenomena in waterand oil-based power-control hydraulics. Journal of Vibroengineering, vol. 16, no. 1, p. 401-411.

[12] Šimic, M., Debevec, M., Herakovič, N. (2014). Modelling of hydraulic spool-valves with special designed metering edges. Strojniški vestnik - Journal of Mechanical Engineering, vol. 60, no. 2, p. 77-83, DOI:10.5545/sv-jme.2013.1104.

[13] Tič, V., Lovrec, D. (2012). Design of Modern Hydraulic Tank Using Fluid Flow Simulation. International Journal of Simulation Modelling, vol. 11, no. 2, p. 7788, DOI:10.2507/IJSIMM11(2)2.202.

[14] Jošt, D., Škerlavaj, A., Lipej, A. (2014). Improvement of efficiency prediction for a Kaplan turbine with advanced turbulence models. Strojniški vestnik Journal of Mechanical Engineering, vol. 60, no. 2, p. 124-134, DOI:10.5545/sv-jme.2013.1222.

[15] Wang, C.M., Li, C.X., Yin, X. (2000). Experimental research on the hydraulic performance of jet pump. Pump Technology, no. 5, p. 3-7, p. 26. (in Chinese)

[16] Zhang, D.S. (2011). Research on the Design Theory and Key Technologies of Large Power Valve-Control Hydrodynamic Coupling. China University of Mining \& Technology, Xuzhou. (in Chinese) 